\author{
Adam Sagan \\ Cracow University of Economics \\ Department of Market Analysis and Marketing Research \\ e-mail: sagana@uek.krakow.pl
}

\title{
Dynamic Structural Equation Models in Momentary Assessment in Consumer Research
}

\section{JEL code: M31}

Keywords: experience sampling method, consumer momentary assessment, dynamic structural equation models

Summary. The aim of the paper is to provide methodological framework to model intensive longitudinal data (ILD). The specific types of such data are consumer moods and emotional feelings that constitute the satisfaction states of the consumer. The research process of ILD involves ecological momentary assessment and experience sampling methods that are characterized by higher ecological validity. In the paper the special type of structural models, namely dynamic structural equation model (DSEM) are developed for proper analysis of multilevel longitudinal data. The models are built on the basis of consumer mood scale. The data were gathered from a convenient sample of 33 respondents and a systematic sample of time moments that provide a total of 640 observations. The results show the insignificant role of the socio-demographic characteristic of the respondents (gender) in explanation of very flexible psychological states.

\section{Introduction}

The measurement of momentary states of the consumers (moods, feelings, physiological reactions, health, facial expression) is related to a specific method of data gathering and sampling that is the experience sampling method (ESM) and ecological momentary assessment (EMA). Originally, the ESM approach was focused on internal experiences (thoughts, feelings, physiological reactions, etc.) in 
a given time moment. In health and medical sciences, the term ecological momentary assessment (EMA) is commonly used to extend ESM and include subjective judgements, health and environmental factors (Stone, Shiffman, 1994).

The objective of ESM/EMA is to capture and test both the place- and timebound phenomena and events that cannot be emulated in laboratory/experimental and survey-based methods. In comparison to experiments and surveys, the realworld and real-time context of data gathering enable to obtain a higher level of the ecological validity of research. The ecological validity stems from the fact that the ESM/EMA measurement is very close to the moment when the measured event occurs. Therefore, the responses have lower recall and reconstruction biases. The sources of bias can be rooted in a telescopic error, phantom responses, retrospective biases like personal heuristics, recency, salience and mood-congruent memory effects.

Additionally, the measurements are taken over-time, so it produces large number of repeated observations that are basis for identification of within-person processes, temporal dynamics and trajectories and response sensitivity over time. Although these two methods are strongly interlinked, EMA is very popular in clinical research and medicine and ESM in psychology, education, management and marketing applications. In marketing research, the experience sampling method is very rarely used but may be applied in the area of Consumer Experience Marketing, and related fields like customer journey research (CJR) and quality of life analysis (QoL). The application of ESM/EMA in marketing seems to be very promising.

The objective of the article is to broaden the scope of consumer research and to model the level of nano-structures of consumer behaviour that are consumer journeys, psychophysiological reactions, moods and feelings. These types of consumer reactions are very important for identification and modelling the consumers' satisfaction states with respect to product-services. Especially, in the modelling the perceived service process quality, the identification and explanation of temporal dynamics of consumer mood are crucial for understanding the satisfaction feelings. However, the very labile emotional states are hardly explained. In modelling the mood states of the consumer, the special type of recently developed structural equation models for intensive longitudinal data (DESM/RDSEM) are used.

\section{ESM data}

On the contrary to experimental and survey-based techniques, the collection of momentary data is based on variety of self-report techniques. There are multiple self-report assessment methods using traditional paper-and-pencil devices (P \& P) and modern mobile technologies. Data gathering methods includes a) daily diaries, b) experience sampling forms, c) electronically activated recording systems 
(EAR), d) smartphones, smartwatches, smartglasses, e) personal tracking devices like emotive insights, pip biofeedbacks, spire stones, spire health tags, SCRAM systems for alcohol level measurement, etc. Daily diaries and experience sampling forms are very often used $\mathrm{P} \& \mathrm{P}$ techniques for qualitative and quantitative deconstruction of consumer's time maps and consumer journeys. Also, smartphones and web surveys are very popular methods of data gathering in marketing.

There are plenty of mobile-web survey platforms like Survey Monkey and Survey Signa and smartphone applications (i.e. iForm, iSurvey, DataField, DREAM, mEMA, ESmCapture, MovisensXS, PACO-iOS). Also, popular moodtrackers enable to monitor the emotional feelings (i.e. Moodtrack Diary, Mood Tracker, T2 Moood Tracker, Moodlytics, Moody, etc.). Personal tracking devices are related rather to monitor the psycho-physiological and health-related reactions, however some of them (facial expressions, blood pressure) serve as indicators of the latent emotional state of the consumers.

The intensive longitudinal data are gathered on the level of individual consumers. It shapes the hierarchical and multilevel structure of data that needs specific approaches to data analysis and modelling (Nezlek, 2012). Measurement moments are nested in time (days, weeks, etc.), time stamps are nested in respondents and finally, the respondents can be nested in the families, social and brand-oriented groups or other institutions. The sampling of experiences (time moments) is usually computer-aided. The computer packages like Experience Sampling, Experience Sampler, Pendragon Software, LifeData, Survey Signal can assist the process of sample selection. Sampling process is technologically intensive. Respondents should be equipped with pagers or smartphones that send the random beeps during the day. Each of the respondent fulfils short experience sampling form (ESF) concerning their actions, presence of others, surrounding, feelings, emotional states (happiness, sadness, satisfaction, stress, anger, etc.). The sampling units are therefore related to person-situation (person-event) interactions in real-time and realplace context.

The average number of time points per respondent sampled is 5-12 during the day and 1-3 weeks of observation. As a result each respondent is characterized by 35-210 time moments during the whole period of data gathering. The non-response rate decreases as the rate of contact per respondent increases. As Hektner, Schmidt, Csikszentmihalyi (2012) suggest average response rate at 1-2 contact a day is $90 \%$ but increasing the number of contacts to $8-10$ would decrease the response rate to $50-80 \%$. Therefore, the greater representativeness of the sample, the higher nonresponse error and sample bias. Specifically, experience sampling belongs to highly obtrusive methods of data gathering, violating the privacy and intimacy of the re- 
spondent. It enables the high level of consumer involvement. Also, the self-selection bias is relatively high (i.e. refusals, self-censorship, socially desirable behaviour).

There are three strategies of experience sampling: a) time-based sampling, b) event-focused (event-contingent) sampling and c) mixed sampling as a combination of time-based and event-focused (Hektner, Schmidt, Csikszentmihalyi, 2012; Trull, Ebner-Priemer, 2009). In time-based sampling schemes, the random sampling (signal-contingent) or fixed sampling (interval-contingent) can be used. A simple random sample consists of a random selection of time during the day in which the respondent is asked to respond. It is used when there is no need to take into account contextual factors for given emotional states (working time vs. free time) and when the respondent's behaviour is not expected to occur at specific time points (e.g. morning or noon). Time-based sampling is generated using the electronic forms of sampling moments of time (beeper studies). It enables random selection of time moments distributed throughout the day and is preferred when it is necessary to obtain high-frequency contacts (about 10-20 during the day). However, it is less convenient for respondents and requires electronic forms of communication (pager, telephone, etc.).

The fixed sampling is used when time points are drawing at specific time of the day. It resembles a random systematic sampling in which respondents are asked to reveal their behaviours and attitudes at specific time intervals, e.g. every 2-4 hours for interview and every 15-30 minutes for a short voice response (EAR). It is most often used to collect data on relatively frequent and cyclical behaviours and experiences of respondents with the use of daily consumer diary. Its advantage is low cost and convenience in implementation and less inconvenience for respondents due to predictability of test moments.

A fixed random sample is used to draw time points at specific time of the day. It resembles a random systematic sampling, in which respondents are asked to reveal their behaviour and attitudes at specific time intervals, e.g. every 2-4 hours for an interview and every 15-30 minutes for a short voice response (EAR). It is most often used to collect data on relatively frequent and cyclical behaviour and experiences of respondents using daily consumer diaries. Its advantage is low cost and convenience in implementation. Respondents can relatively easily predict the survey moments. In the case of irregular events occurring in specific situations, it may provide biased results.

In an event-oriented sample, time points are selected when certain events that occur during the day (e.g. going to work or school, meeting friends, entering a shop, lunch, etc.). This type of sampling scheme is used for atypical and less frequent events, social interactions, and when the researcher has a predefined list of events to be analyzed. It entails the necessity of training the respondents in the correct recognition of the examined events, which take place at moderate intervals (they 
are neither too frequent nor too rare). Usually, the saturation of the sample takes place after the identification of about 30 events by one respondent.

\section{Models for ESM data}

Modelling of intensive longitudinal data on the individual respondent level can be regarded from various perspectives. Bolger and Laurenceau (2013) distinguish three types of research questions: 1) aggregation over time, 2) modelling the time course and 3) analyzing the within-person, between persons and between-time processes. High intensity of longitudinal data enables quantitative analysis. The analytical approaches involve multilevel hierarchical and non-hierarchical models because:

- measurement moments are nested in time (days, weeks),

- time is nested in respondents,

- respondents are nested in social groups/institutions.

The most general approach to model ESM data is based on multilevel structural equation modelling ${ }^{1}$. Many dynamic analytical frameworks have been recently developed like cross-classified multilevel structural equation modelling, dynamic structural equation modelling (DSEM), residual dynamic structural equation modelling (RDSEM). DSEM is general approach to the analysis of intensive longitudinal data that incorporates time series analysis, latent variable modelling, multilevel models and time - varying effect modelling (Asparouhov, Hamaker, Muthen, 2018).

In the family of cross-classified DSEM models four sources of correlation are decomposed: 1/ specific inter-individual variability (multilevel modelling), 2/ data autocorrelation due to measurement proximity or nonindependence (time series modelling), 3/ correlations between variables (structural equations modelling) and 4/ correlations due to the same stage of evolutionary process (time-varying effect modeling) (Tan et al., 2010). Specifically, types of DSEM models can be divided with respect to a number of levels that are taken into account and need of accounting for interpretation of structural part of a model is based on specificity of longitudinal data. Regarding this fact, general multilevel non-hierarchical random effects structural equation model (DSEM model), general multilevel nonhierarchical random effects residual structural equation model (RDSEM model), two-level hierarchical random effect model (measurements are nested in the respondents only), $\mathrm{N}=1$ uni-level model of time series (lack of nested data) can be distinguished. Additionally, ordinary time-series models (ARMA, ARIMA) are special cases of DSEM and RDEM models.

\footnotetext{
${ }^{1}$ The cross-classified DSEM models can be estimated by the latest version of Mplus 8.2 (Muthen, Muthen, 2017).
} 
In DSEM model decomposition of variability is based on decomposition of individual-level measurement in time $t$ for between-respondents, between-time variability (Asparouhov, Hamaker, Muthen, 2018):

$$
Y_{i t}=Y_{1, i t}+Y_{2, i}+Y_{3, t}
$$

$\mathrm{Y}_{\mathrm{it}}-$ measurement of dependent variable for respondent $i$ in time $t$

$\mathrm{Y}_{1, \mathrm{it}}-$ residuals $\left(\mathrm{Y}_{1, \mathrm{it}}=\mathrm{Y}_{\mathrm{it}}-\mathrm{Y}_{2, \mathrm{i}}-\mathrm{Y}_{3, \mathrm{t}}\right)$

$\mathrm{Y}_{2, \mathrm{i}}$ - between-respondents variability

$\mathrm{Y}_{3, \mathrm{t}}$ - between-time variability

The decomposition above, involves the non-hierarchical multilevel model in which within-group and between-group measurement models as well as respondent- and time-specific structural model are developed.

The within-group measurement model is given in equation 2 .

$Y_{1, i t}=\tau_{1}+\sum_{l=0}^{L} \Lambda_{1, l} \eta_{1, i, t-l}+\sum_{l=0}^{L} R_{l} Y_{1, i, t-l}+\sum_{l=0}^{L} K_{1, l} X_{1, i, t-l}+\varepsilon_{1, i t}$

$\mathrm{X}_{1, \mathrm{i}, \mathrm{t}-1}-$ lagged covariate

$\eta_{1, \mathrm{i}, \mathrm{t}-1}-$ respondent-specific lagged latent variable

In the within-group model the measurement of respondent $i$ in given time $t$ is function of lagged dependent variable $\left(\mathrm{Y}_{1, \mathrm{i}, \mathrm{t}-1}\right)$, lagged covariate $\left(\mathrm{X}_{\mathrm{i}, \mathrm{t}-\mathrm{l}}\right)$ and lagged respondent - specific latent variable.

The between-group measurement model on respondent level is given in equation 3.

$Y_{2, i}=v_{2}+\Lambda_{2} \eta_{2, i}+K_{2} X_{2, i}+\varepsilon_{2, i}$

$\mathrm{X}_{2, \mathrm{i}}$ - respondent-specific covariate

$\eta_{2, \mathrm{i}}-$ respondent-specific but time-invariant latent variable

In the between-group measurement model, the individual responses are a function of respondent-specific covariate (Xi) and time-invariant latent variable on the individual level.

The between-group measurement model on time level is presented in equation 4.

$$
Y_{3, t}=v_{3}+\Lambda_{3} \eta_{3, t}+K_{3} X_{3, t}+\varepsilon_{3, t}
$$

$\mathrm{X}_{3, \mathrm{t}}$ - time-specific covariate

$\eta_{3, t}$ - time-specific but respondent-invariant latent variable

The between-group measurement model on time level is characterized by time-specific covariate $\left(\mathrm{X}_{\mathrm{t}}\right)$ and latent variable that is time-specific but respondent-invariant.

The structural part of the model consists of two parts: respondent-specific and time-specific structural model.

The respondent-specific structural model is given in equation 5 . 
$\eta_{2, i}=a_{2}+B_{2} \eta_{2, i}+\Gamma_{2} X_{2, i}+\zeta_{2, i}$

$\mathrm{X}_{2, \mathrm{i}}$ - respondent-specific covariate

In the respondent-specific structural model, the latent variables on the individual level is explained by other endogenous latent variables and respondentspecific covariate $\left(\mathrm{X}_{\mathrm{i}}\right)$.

The time-specific structural model is presented in equation 6 .

$\eta_{3, t}=a_{3}+B_{3} \eta_{3, t}+\Gamma_{3} X_{3, t}+\zeta_{3, t}$

$\mathrm{X}_{3, \mathrm{t}}$ - time-specific covariate

In the time-specific structural model, the latent variables on the time level is explained by other endogenous latent variables on that level and time-specific covariate $\left(\mathrm{X}_{\mathrm{t}}\right)$.

The residual dynamic structural equation model (RDSEM) is a version of DSEM that fills the gap between time-series DSEM (structural relations across between-time variables) and the multilevel longitudinal model (contemporaneous relations between the variables). The RDSEM model assumes the separation of structural and autoregressive parts of the within-level measurement model. The autoregressive part is absorbed by a model of residuals that takes into account the dependencies among measurements. On the other hand, the structural part is based on the relations between variables (without lags). This type of model enables the interpretation of the cross-sectional structural model that is built on timeseries data. As the special case of DSEM, in RDSEM model the residuals are treated as latent variables and variances of the new residuals of the models are fixed to a small positive number (Asparouhov, Muthen, 2018). In RDSEM model the between-level model is the same as in DSEM. Decomposition of the withinlevel model into the structural part and the autoregressive part includes the residuals for dependent and latent variables in the structural and autoregressive part of the within-level model.

The structural part of the within-level model is shown in equations 7 and 8.

$$
\begin{aligned}
& Y_{1, i t}=\tau_{1}+\Lambda_{1,0} \eta_{1, i t}+R_{0} Y_{1, i t}+K_{1.0} X_{1, i t}+\hat{Y}_{1, i t} \\
& \eta_{1, i t}=a_{1}+B_{1,0} \eta_{1, i t}+Q_{0} Y_{1, i t}+\Gamma_{1.0} X_{1, i t}+\hat{\eta}_{1, i t}
\end{aligned}
$$

The variables $\hat{Y}_{1, \mathrm{it}}$ and $\tilde{\eta}_{1, \mathrm{it}}$ are regarded as residual variables (without autoregressive relations).

The autoregressive part of the within-level model is given in equation 9 and 10.

$\hat{Y}_{1, i t}=\sum_{l=0}^{L} \Lambda_{1, l} \hat{\eta}_{1, i, t-l}+\sum_{l=0}^{L} R_{l} \hat{Y}_{1, i, t-l}+\varepsilon_{1, i t}$ 
$\hat{\eta}_{1, i t}=\sum_{l=0}^{L} B_{1, l} \hat{\eta}_{1, i, t-l}+\sum_{l=0}^{L} \hat{Q}_{l} \hat{Y}_{1, i, t-l}+\zeta_{1, i t}$

In the autoregressive part of the model, the residuals of dependent and latent variables are explained by the same residual variables with lags. The choice between DSEM and RDSEM models depends on the purpose of modelling. As T. Asparouhov and B. Muthen suggest (2018), DSEM models explain structural relations across time, whereas RDESM are used to model contemporaneous relations between the variables on time-series data.

\section{DSEM models of customer mood}

The application of DSEM model in consumer research is mostly related to mood and feelings data. In the following section, the modelling of individual time-series is based on the data gathered on the convenient sample of 33 respondents (young consumers) from Southern part of Poland (university students) ${ }^{2}$. The data were taken from the systematic sample of time moments during the day (3 measurement occasions: in the morning, afternoon and evening). Because of $\mathrm{P} \& \mathrm{P}$ format of experience sampling form, single 10-point Likert scale of bi-polar mood was used, with no multi-item scales. Additionally, gender served as a covariate on respondent level only.

On the basis of intensive longitudinal data, three models were developed, namely uni-level model of time-series for $\mathrm{N}=1$, DSEM/RDSEM two-level models with random effects on respondent level and three-level DSEM model with random effects for respondent and time level. The final model of cross-classified dynamic confirmatory factor model are developed and presented, with Bayesian estimation of the parameters. In Bayesian estimation of the parameters, the Mplus 8.2 was used $^{3}$.

Because of multilevel cross-classified structure of data, the intraclass correlation coefficients (ICC) for both respondent and time levels have been calculated. The ICC shows the relationship between group-level and the sum of grouplevel and individual-level variability. The high ICC suggests strong inter-correlation within-level units and violation of independence of observation assumption. The formula of ICC is given in equation 11.

$$
I C C=\frac{\sigma_{B}}{\sigma_{W}+\sigma_{B}}
$$

\footnotetext{
${ }^{2}$ Convenient sample was used due to technical and organizational problems with random sample selection on individual level.

${ }^{3}$ In Bayesian estimation non-informative priors and two chains of MCMC were used (half of iteration were burnt). For observed dependent variable (Mood) and regression coefficients normal priors was used $(0$, infinity). For residual variances inverse gamma priors were used $(-1,0)$.
} 
$\sigma_{\mathrm{B}}-$ between-level variance

$\sigma_{\mathrm{W}}-$ within-level variance

In order to calculate ICC, the baseline cross-classified model with random intercept of mood was calculated. The estimates for the baseline model with no predictors and latent variable structure is depicted in Table 1.

Table 1

Intraclass correlations

\begin{tabular}{|l|c|c|}
\hline \multicolumn{1}{|c|}{ Level } & Estimates of $\operatorname{mood}$ & ICC \\
\hline Within & 19.920 & - \\
\hline Between-time & 0.192 & 0.009 \\
\hline Between-respondents & 0.099 & 0.005 \\
\hline
\end{tabular}

Source: own research based on Mplus 8.2.

The low value of the intraclass correlation coefficient indicates a very small unexplained variance of dependent variable (mood) on both levels and lack of necessity to include predictors from respondent- and time- level to explain the within-level inter-correlation.

In order to check this assumption, the within-level model and between-level models on respondent and time levels were estimated. The gender was used as predictor on the respondent level. The estimation of parameters, the autoregressive single-indicator factor model has been used. The stability of parameters estimation and distribution of key parameters (variance of mood and gender - mood regression) under study (trace plots and posterior distribution of parameters) is depicted on Figure 1.
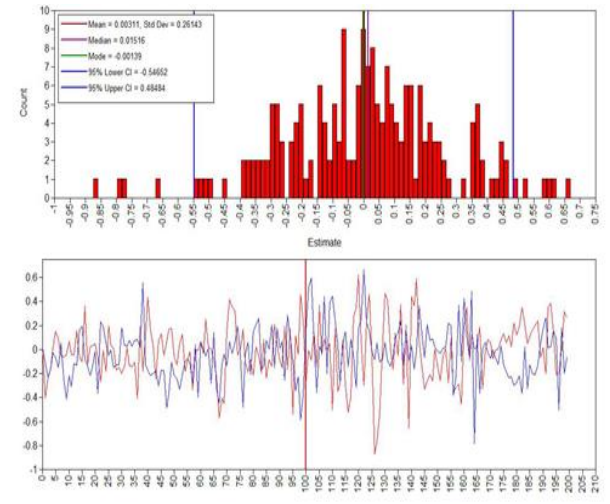

Mood
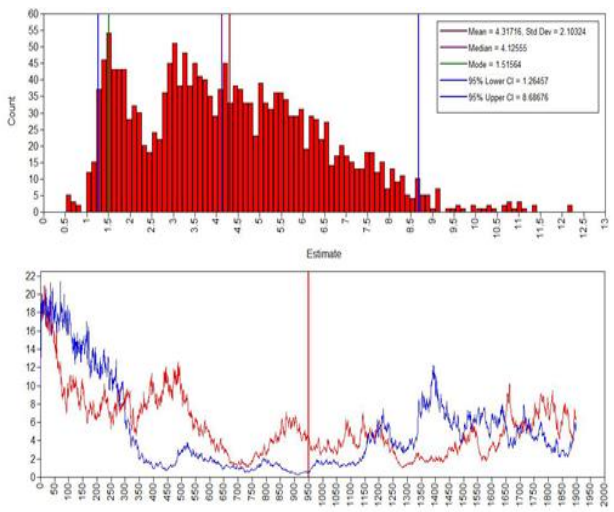

Gender - mood

Figure 1. Distribution of parameters and trace plots of variable mood and regression gender-mood

Source: own research based on Mplus 8.2. 
The parameters distribution of estimated parameters shows mood variances. The within-level model is presented in Table 2 (upper panel). The point estimate of the parameters is taken as a median of distribution. The lower panel presents two MCMC chains that show the stability of estimates across MCMC iterations.

Table 2 includes parameters of the within-level model. The mood is measured as single-item latent variable with fixed factor loading as 1 . There is a significant and positive autocorrelation between factor and lagged factor, so the mood in $t-1$ period influences the mood in $t$.

Table 2

Within level model

\begin{tabular}{|l|c|c|c|}
\hline \multicolumn{1}{|c|}{ Variables } & Estimates & Posterior s.d. & P-value \\
\hline F $->$ Mood & 1.000 & 0.000 & 0.000 \\
\hline F-1 -> F & 0.250 & 0.050 & 0.000 \\
\hline Residual Mood & 4.126 & 2.104 & 0.000 \\
\hline Residual F & 15.014 & 2.350 & 0.000 \\
\hline
\end{tabular}

Source: own research based on Mplus 8.2.

Between-level models are estimated in cross-classified framework of multilevel analysis because individual measurement moments are nested in time (days) and respondents, but the latter grouping variables are not hierarchical (each respondent is nested in various (all) time points and in each day are nested all of the respondents).

The between-day level model is presented in Table 3. On time level, no time-specific covariate is used, so the variance of mood factor and error variance of mood are calculated.

Table 3

Between-day level model

\begin{tabular}{|l|c|c|c|}
\hline \multicolumn{1}{|c|}{ Variables } & Estimates & Posterior s.d. & P-value \\
\hline F $->$ Mood & 1.000 & 0.000 & 0.000 \\
\hline Variance F & 0.252 & 0.971 & 0.000 \\
\hline Residual Mood & 0.277 & 1.296 & 0.000 \\
\hline
\end{tabular}

Source: own research based on Mplus 8.2.

Variance of mood factor is significant, so it indicates the mood differences across days. The distribution of mood over week days shows a relatively higher level of positive mood at week-ends in comparison to the beginning of the week. It is shown in Figure 2. 


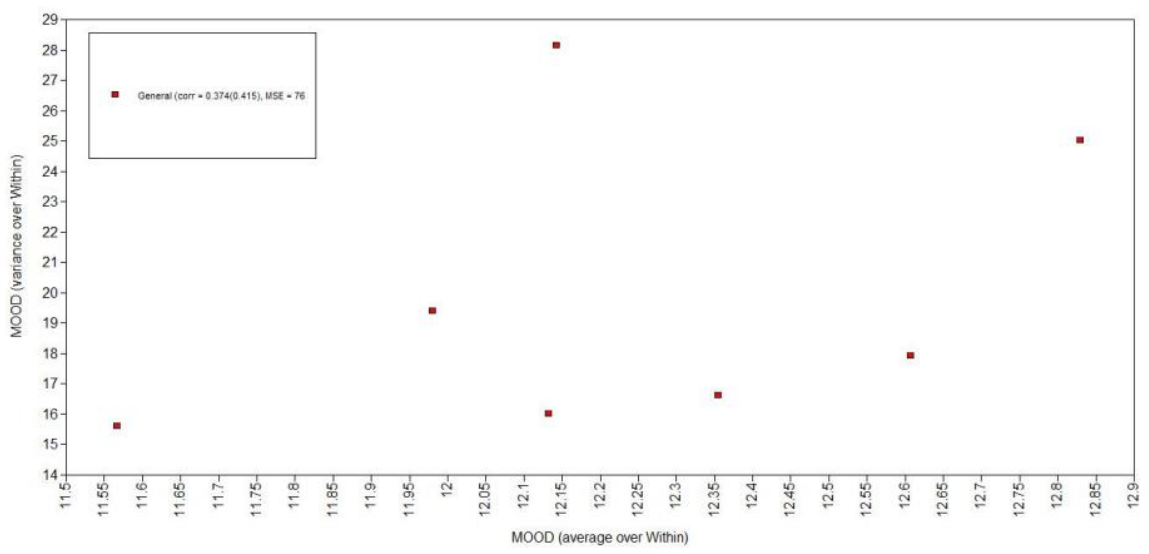

Figure 2. Means and variances of mood across weekdays

Source: own research based on Mplus 8.2.

The between-respondent level model is presented in Table 3 .

Table 3

Between - respondent level model

\begin{tabular}{|l|c|c|c|}
\hline \multicolumn{1}{|c|}{ Variables } & Estimates & Posterior s.d. & P-value \\
\hline F ->Mood & 1.000 & 0.000 & 0.000 \\
\hline Gender $->$ F & 0.012 & 0.246 & 0.467 \\
\hline Residual Mood & 0.154 & 0.211 & 0.000 \\
\hline Residual F & 0.167 & 0.273 & 0.000 \\
\hline
\end{tabular}

Source: own research based on Mplus 8.2.

Table 3 presents the parameters of the between-respondent level that include regression between gender (time-invariant covariate) and mood. The parameter is insignificant and therefore being the males (1) rising insignificantly mood by 0.012 in comparison to females (0). Significant disturbance term (residual F) shows that there are unobserved factors that may explain mood variability.

\section{Conclusions}

The non-significant gender parameter across respondents confirms the general presuppositions that such a volatile indicators of latent states as moods and feelings of happiness or satisfaction can hardly be explained by time- or respondentinvariant attributes. Therefore, one can stress that "De Gustibus Non Est Explanandum" and the low ICC across time and respondents indicates no substantial 
predictors that explain the between-level variability of the mood. However, finding time- and respondent-varying covariate on within-level may enhance the explanatory power of the model.

Further development of mood measurement like dynamic factor analysis (DCFA), Dynamic IRT models (DIRT), Dynamic latent state-trait models (DLST) is needed. The DSEM models are promising methods of intensive longitudinal data analysis on respondent level that overcome the problems with ecological validity and accuracy of measurement scales that are used to identify very flexible states of consumer moods and feelings.

\section{Bibliography}

Asparouhov, T., Hamaker, E.L., Muthen, B.O. (2018). Dynamic Structural Equation Models. Structural Equation Modeling: A Multidisciplinary Journal, 25 (3), 359-388.

Asparouhov, T., Muthen, B.O. (2018). Comparison of Models for the Analysis of Intensive Longitudinal Data. Retrieved from: http://www.statmodel.com/download/RDSEM.pdf.

Bolger, N., Laurenceau, J. (2013). Intensive Longitudinal Methods: An Introduction to Diary and Experience Sampling Research. New York: Guilford.

Hektner, J.M., Schmidt, J.A., Csikszentmihalyi, M. (2012). Experience Sampling Method: Measuring the Quality of Everyday Life. Thousand Oaks, CA: Sage.

Muthen, B.O., Muthen, L.O. (2017). Mplus. Statistical Analysis with Latent Variables. User Guide. Los Angeles: Muthen \& Muthen.

Nezlek, J.B. (2012). Multilevel Modeling Analyses of Diary-Style Data. In: M.R. Mehl, T.S. Conner, Handbook of Research Methods for Studying Daily Life. New York: Guilford Press.

Stone, A., Shiffman, S. (1994). Ecological Momentary Assessment (EMA) in Behavioral Medicine. Annals of Behavioral Medicine, 16 (3), 199-202.

Tan, X., Shiyko, MP., Li, R., Li, Y., Dierker, L. (2010). Intensive Longitudinal Data and Model with Varying Effects (Technical Report No 10-106). University Park, PA: The Methodology Center, The Pennsylvania State University.

Trull, T.J., Ebner-Priemer, U. W. (2009). Using Experience Sampling Methods/Ecological Momentary Assessment (ESM/EMA) in Clinical Assessment and Clinical Research: Introduction to the Special Section. Psychological Assessment, 21 (4), 457-462.

Zhang, Z., Hamaker, E., Nesselroade, J. (2008). Comparisons of Four Methods for Estimating a Dynamic Factor Model. Structural Equation Modeling, 15, 377-402.

\section{Dynamiczne modele równań strukturalnych w ocenie chwilowej w badaniach konsumenckich}

Slowa kluczowe: metoda próbkowania doświadczeń, ocena chwilowa klientów, modele dynamicznego równania strukturalnego

Streszczenie. Celem artykułu jest dostarczenie metodologicznych ram modelowania intensywnych danych wzdłużnych (ILD). Specyficzne rodzaje takich danych to nastroje konsumenckie i uczucia emocjonalne, które stanowią stany zadowolenia konsumenta. Proces badawczy ILD obejmuje oceny chwilowych stanów konsumenckich i prób procesowych, które charakteryzują się wyższą trafnością ekologiczną. W artykule opracowano 
specjalny typ modeli strukturalnych, a mianowicie dynamiczne modele równań strukturalnych (DSEM) do analizy wielopoziomowych danych wzdłużnych. Modele budowane są na podstawie skali nastrojów konsumenckich. Dane zebrano z dogodnej próby 33 respondentów i systematycznej próby losowej momentów czasowych, która daje łącznie 640 obserwacji. Wyniki wskazują na nieistotną rolę charakterystyk społeczno-demograficznych respondentów (płci) w wyjaśnianiu bardzo zmiennych i niestabilnych stanów emocjonalnych klientów.

\section{Citation}

Sagan, A. (2018). Dynamic Structural Equation Models in Momentary Assessment in Consumer Research. Marketing i Zarzadzanie, 4 (54), 61-73. DOI: 10.18276/miz.2018.54-05. 